\title{
Antioxidant properties of high molecular weight compounds from coffee roasting and brewing byproducts
}

\author{
Amaia Iriondo-DeHond ${ }^{1}$, Beatriz Ramírez ${ }^{1}$, Francisco Velazquez Escobar ${ }^{2,3}$ and María \\ Dolores del Castillo ${ }^{1 *}$
}

${ }^{1}$ Instituto de Investigación en Ciencias de la Alimentación (CIAL) (CSIC-UAM), C/ Nicolás Cabrera, 9, Campus de la Universidad Autónoma de Madrid, 28049 Madrid, Spain; ${ }^{2}$ Technische Universität Berlin, 135/PC14 Max Volmer Laboratorium für Biophysikalische Chemie, 1023 Berlin, Germany; ${ }^{3}$ Caffeine bioanalytics, Krumme Str. 92, 10585 Berlin, Germany

Corresponding author: María Dolores del Castillo, Instituto de Investigación en Ciencias de la Alimentación

Submission date: December $3^{\text {rd }}$, 2018, Acceptance Date: March $28^{\text {th }}$, 2019, Publication Date: March 31 $1^{\text {st }}, 2019$

Citation: Iriondo-DeHond A., Ramirez B., Escobar F.V., del Castillo M.D. Antioxidant properties of high molecular weight compounds from coffee roasting and brewing byproducts. Bioactive Compounds in Health and Disease 2019; 2(3):48-63. DOI: https://doi.org/10.31989/bchd.v2i3.588

\begin{abstract}
Coffee is one of the main sources of dietary melanoidins. Coffee melanoidins have antioxidant properties and are associated with protective effects against oxidative damage. The aim of this research was to study the potential of melanoidins obtained from coffee byproducts as functional ingredients to improve gastrointestinal health using normal human colon cells. Melanoidins were extracted from two coffee byproducts: coffee silverskin (CS) and spent coffee grounds (SCG). Extraction was carried out by ultrafiltration using a $10 \mathrm{kDa}$ molecular cut membrane. Safety of raw materials and isolated fractions was studied by microbiological analysis and determination of acrylamide, respectively. Characterization of coffee isolates was assessed by UV-Vis absorption spectroscopy, infrared spectroscopy, and determination of browning and protein content. The antioxidant capacity was measured by ABTS and formation of intracellular ROS in human intestinal cells (CCD18 cell line). The high molecular weight (HMW) enriched fraction showed antioxidant capacity and protected intestinal cells against induced oxidative stress. Coffee byproducts obtained after the roasting process are a sustainable source of melanoidins that may act as antioxidants and therefore, may have the potential to be used as a functional novel ingredient for the prevention of gastrointestinal diseases caused by oxidative stress.
\end{abstract}

Keywords: Coffee byproducts, melanoidins, gastrointestinal health, sustainable health. 


\section{INTRODUCTION}

The main sources of dietary melanoidins are coffee and bakery products. Melanoidins are one of the major components of coffee beverages, representing up to the $25 \%$ of dry matter [1]. Global dietary intake of melanoidins from coffee ranges from approximately 5 to $40 \mathrm{mg} / \mathrm{kg} / \mathrm{day}$ [2]. Melanoidins comprehend high molecular weight nitrogen-containing compounds that are formed during the roasting process. Here, the green coffee beans experience substantial chemical and structural changes. At a molecular level and as a product of the last stage of the Maillard reaction, polysaccharides, proteins and phenolic compounds are thermochemically transformed into melanoidins [3].

Within the whole coffee fruit value chain, $90 \%$ is discarded as an agricultural waste or byproduct [4]. Coffee silverskin (CS) and spent coffee grounds (SCG) are main coffee industry residues $[5,6]$. Since these byproducts are generated after the roasting process of coffee beans, they may be considered an important sustainable source of melanoidins [7].

Although the chemical structure of melanoidins is widely unknown, many healthpromoting properties have been associated to these compounds, such as antioxidant, antimicrobial, anti-inflammatory, antihypertensive or prebiotic activity [7]. The most antioxidant melanoidins are those obtained from coffee when compared to other thermally processed foods such as chocolate, sweet wine, balsamic vinegar, beer, bread, breakfast cereals and biscuits [8]. The antioxidant capacity of coffee melanoidins has been associated with protective effects against oxidative damage. Studies have shown that the high molecular weight (HMW) fraction of coffee brews subjected to in vitro fermentation for $24 \mathrm{~h}$ with human fecal bacteria possessed antioxidant activity [9]. Therefore, roasted coffee could be considered as a major source of dietary antioxidants that provide protection to the intestine during a normal gastrointestinal transit time against radical stress in colon.

Considering the vast amount of waste production in current market schemes, it is of great interest to consider coffee byproducts, CS and SCG as a sustainable source of melanoidins. The aim of the present study was to obtain antioxidant HMW fractions enriched in melanoidins from coffee byproducts implementing a simple, environmental-friendly and sustainable process. Therefore, preliminary studies regarding the potential effect of risk reduction of gastrointestinal pathologies associated with oxidative stress were carried out in human intestinal cells.

\section{Materials and methods}

Raw material

CS from roasted Arabica coffee beans (Coffea arabica) was provided by Fortaleza S.A. (Spain). Coffee silverskin extract (CSE) was produced as previously described [10]. Briefly, $50 \mathrm{mg}$ of coffee silverskin were added per water milliliter. This mixture was stirred for 10 minutes at $100{ }^{\circ} \mathrm{C}$ and filtered. The filtrate was freeze-dried. Moisture content of powdered CSE was calculated according to AOAC (1999) and it corresponded to $6.5 \%$.

SCG from natural $50 \%$ Arabica $50 \%$ Robusta roasted beans from a local restaurant were pelletized for their storage until analysis (PelletSolucion S.L., Salamanca, Spain). Pelletization allowed reducing water content of SCG. After pelletization, thermal stabilization of SCG was carried out at $109{ }^{\circ} \mathrm{C}$ for 1 hour. Gravimetric measurements were made to constant weight. 
Microbiological analyses of raw materials

CSE and SCG were microbiologically analyzed to evaluate the safety of their use as food ingredients. Count of (1) total aerobic microorganisms, (2) aerobic microorganisms forming endospores and (3) molds and yeasts were carried out. All assays were performed in sterile conditions, including previous solubilization of $10 \mathrm{~g}$ of CSE or SCG in BPW (90 mL) by using a stomacher (230 rpm, $1 \mathrm{~min}$ ). Different conditions were set for each analysis: (1) pour plate method, PCA medium, incubation at $30{ }^{\circ} \mathrm{C} 72 \mathrm{~h}$; (2) pour plate, BHI agar medium, preincubation $\left(80^{\circ} \mathrm{C}, 10 \mathrm{~min}\right)$ and incubation at $37^{\circ} \mathrm{C} 48 \mathrm{~h}$; and (3) spread method, SDA with chloramphenicol and incubation at $25{ }^{\circ} \mathrm{C} 120 \mathrm{~h}$. Results were expressed as colony forming units $(\mathrm{CFU}) / \mathrm{g}$.

\section{Extraction of melanoidins}

Prior to ultrafiltration, CSE was prepared in an aqueous solution at $2 \mathrm{mg} / \mathrm{mL}$. Stabilized SCG were suspended in water at $14 \% \mathrm{w} / \mathrm{v}$, incubated at $121{ }^{\circ} \mathrm{C}$ for 20 minutes. The soluble fraction was separated by centrifugation at 5,000 rpm for 12 minutes and subjected to gravimetric filtration. A HMW fraction enriched in melanoidins was obtained from CSE and SCG by ultrafiltration using a $10 \mathrm{kDa}$ Omega 76MM molecular cut membrane with an Amicon Stirred Ultrafiltration Cell. HMW melanoidin fractions were freeze-dried and stored until analysis. The isolation process was carried out in triplicate.

\section{Melanoidin fraction characterization}

$U V$-Visible absorption spectroscopy

UV-Vis spectrum of caramel standard and melanoidin enriched fractions $(0.5 \mathrm{mg} / \mathrm{ml})$ was acquired using a microplate reader (BioTek Epoch 2 Microplate Spectrophotometer, Winooski, VT, USA). Sulfite ammonia caramel (E-150d) was used as a melanoidin standard. Caramel is formed in a Maillard-type reaction where carbonyl compounds react with amino groups or ammonia [11]. Analytical determination was carried out in triplicate. Absorption spectra were recorded between 240 and $720 \mathrm{~nm}$ at room temperature.

\section{Infrared spectroscopy (IR)}

IR spectra of caramel, CSE, SCG and corresponding HMW melanoidin fractions were recorded in a Tensor27 (Bruker) mid-infrared spectrometer equipped with a liquid nitrogen cooled MCT-detector, a Rocksolid ${ }^{\mathrm{TM}}$ interferometer and a Durascope ${ }^{\mathrm{TM}}$ diamond ATR-cell. Prior sample IR spectrum recording (200 scans), a background reference was measured (400 scans). After each experiment, the diamond crystal was cleaned with distilled water (Millipore-quality) and ethanol (chromatographic grade). IR spectra were analyzed using the OPUS (Bruker) software. Base-line corrected spectra were plotted using the OriginLab Software (V10.X). Characteristic IR bands are observed within a low- $\left(750-1800 \mathrm{~cm}^{-1}\right)$ and high-frequency (2700$3400 \mathrm{~cm}^{-1}$ ) window.

\section{Melanoidin content}

The content of melanoidins in samples was determined according to that previously described [12]. HMW extracts were dissolved in water $(1 \mathrm{mg} / \mathrm{mL})$ light-absorption at $405 \mathrm{~nm}$ was performed using a microplate reader (BioTek Epoch 2 Microplate Spectrophotometer, Winooski, VT, USA). Caramel (E-150d) was used as a melanoidin standard. Analytical 
determination was carried out in triplicate. Results were expressed in equivalent milligrams of caramel melanoidins/gram of sample.

\section{Soluble proteins}

Bio-Rad Protein Assay based on the Bradford method was used in a micro-method format to determine protein concentration. Briefly, a solution of Bradford reagent (1:4, reagent:milli-Q water) was prepared and filtered using Whatman 4 filter. Ten $\mu$ l of sample and $200 \mu 1$ of Bradford solution were placed in a multi-well microplate. Samples were incubated for 5 min at room temperature, and the absorbance was measured at $595 \mathrm{~nm}$. Sample blank and reagent blank were also analyzed. A calibration curve was constructed using BSA $(0.05-0.5 \mathrm{mg} / \mathrm{ml})$. All measurements were performed in triplicate. Results were expressed as $\mathrm{mg} \mathrm{BSA} / \mathrm{g}$ of sample.

\section{Total antioxidant capacity}

The trapping capacity of cationic free radicals was evaluated using the method of radical $\mathrm{ABTS}^{\cdot+}$ bleaching described for its use in microplate $[13,14]$. Aqueous solutions of chlorogenic acid (CGA) were used for calibration (0.15-2.0 mM). Absorbance was measured in microplate using a UV-Visible Spectrophotometer (BioTek Epoch 2 Microplate Spectrophotometer, Winooski, VT, USA). All measurements were performed in triplicate and results were expressed as mg CGA equivalents/g of sample.

\section{Acrylamide}

Content of acrylamide was determined by liquid chromatography coupled with tandem mass spectrometry with electrospray ionization operated in positive mode (ESI-MS/MS). HWM fractions from CSE and SCG were dissolved in water $(50 \mathrm{mg} / \mathrm{mL})$. Different concentrations of $\left[{ }^{13} \mathrm{C}_{3}\right]$-acrylamide $(0-80 \mu \mathrm{g} / \mathrm{ml})$ were added as internal standard. Samples $(0.85 \mathrm{~mL})$ were treated with $25 \mu \mathrm{L}$ of each Carrez I and Carrez II solutions and centrifuged 11,600 rpm for 10 min at $4{ }^{\circ} \mathrm{C}$. Supernatants were filtered through $0.45 \mu \mathrm{m}$ pore diameter nylon membrane syringe filters (Análisis Vínicos, Ciudad Real, Spain). A Varian 1200L, with API-ES between 10 and 1500 Da range mass, liquid chromatograph coupled to a Triple Quadrupole MS detector was used. Acrylamide was recorded using multiple reaction monitoring (MRM) mode by selecting ion $\mathrm{m} / \mathrm{z} 72[\mathrm{M}+\mathrm{H}]+$ at the first quadrupole $(\mathrm{Q} 1)$, fragmented in Q2, and analyzing resulting ion $\mathrm{m} / \mathrm{z} 55$ at Q3. The system consisted of two pumps, Varian Prostar 210 and an Phenomenex Aqua C18 (250 mm $\times 4,6 \mathrm{~mm} \mathrm{ID,} 5 \mu \mathrm{m}$, ) column, at a flow rate of $0.5 \mathrm{~mL} / \mathrm{min}$. Acetonitrile containing $0.1 \%$ formic acid (solvent $\mathrm{A}$ ) and $0.1 \%$ formic acid in $\mathrm{H}_{2} \mathrm{O}$ (solvent B) as mobile phase was pumped with the following gradient: $10-50 \%$ solvent $\mathrm{A}(0-10 \mathrm{~min}), 50$ $90 \%$ solvent A (10-11 min), hold 5 min to recover initial conditions. The injection volume was $20 \mu \mathrm{L}$. The limit of the quantitation was set at $20 \mu \mathrm{g} / \mathrm{kg}$. Samples and standard solutions were analyzed in triplicate. Acrylamide content was expressed as $\mu \mathrm{g} / \mathrm{kg}$ dry weight.

\section{Cell studies}

Normal human colon fibroblasts (CCD-18 cell line) were purchased from the American Type Culture Collection (ATCC, Barcelona, Spain). Cells were under passage 10 were cultured as a monolayer in Dulbecco's Modified Eagle Medium (DMEM) supplemented with 10\% v/v heat 
inactivated fetal calf serum (FBS), $50 \mathrm{U} / \mathrm{ml}$ penicillin and $50 \mu \mathrm{g} / \mathrm{ml}$ streptomycin and $1 \% \mathrm{v} / \mathrm{v}$ L-glutamine. Cell cultures were incubated at $37{ }^{\circ} \mathrm{C}$ and $100 \%$ humidity in a $5 \% \mathrm{CO}_{2}$ atmosphere.

\section{Cytotoxicity}

In order to select the non-cytotoxic concentrations for the following intracellular reactive oxygen species (ROS) measurement assays, cell viability was determined by the MTT [3-(4,5dimethylthiazol-2-yl)-2,5-diphenyltetrazolium bromide] assay [15]. Powdered extracts were prepared in phosphate buffered saline (PBS) solution $(10 \mathrm{mM} \mathrm{pH} \mathrm{7.4)} \mathrm{and} \mathrm{sterile} \mathrm{filtered.} \mathrm{First,}$ CCD-18 cells were cultured at a density of $10^{4}$ cells per well of a 96-well plate for $24 \mathrm{~h}$. Then, cells were treated with caramel or the HMW melanoidin fractions of CSE or SCG (10 and 25 $\mu \mathrm{g} / \mathrm{mL}$ ) for $24 \mathrm{~h}$. DMSO (50\%) was used as death control. Subsequently, cells were incubated in MTT solution $(0.5 \mathrm{mg} / \mathrm{mL})$ for $2 \mathrm{~h}$ at $37^{\circ} \mathrm{C}$. The supernatant was then removed, $100 \mu \mathrm{L}$ of DMSO were added and the optical density at $570 \mathrm{~nm}$ was measured using a microplate reader (BioTek Epoch 2 Microplate Spectrophotometer, Winooski, VT, USA). Experiments were carried out in triplicate. Results were expressed as percentage of viability compared to control non-treated cells.

\section{Intracellular ROS}

Intracellular ROS scavenging assay was performed by measuring the fluorescence intensity of the 2',7'-dichloro-dihydro-fluorescein diacetate (DCFH-DA) probe, which is proportional to the amount of ROS formed [16]. A $10 \mathrm{mM}$ solution of DCFH-DA was prepared (5 mg in $1 \mathrm{~mL}$ DMSO), and a $50 \mu \mathrm{L}$ aliquot was separated. Then, $750 \mu \mathrm{L}$ of DMSO were added to the $50 \mu \mathrm{L}$ solution. CCD-18 cells were cultured at a density of $10^{4}$ cells per well of a 96-well plate for 24 h. After 24 hours of caramel or the HMW melanoidin fractions of CSE or SCG (10 and 25 $\mu \mathrm{g} / \mathrm{mL}$ ) incubation, cells were pre-loaded with $2.5 \mu \mathrm{L} /$ well of DCFH-DA for 30 minutes at 37 ${ }^{\circ} \mathrm{C}$. After incubation, DCFH becomes dichlorofluorescein (DCF) due to intracellular oxidants and will emit fluorescence. Next, culture medium was removed; cells were washed with PBS; and caramel or the HMW melanoidin fractions of CSE or SCG (10 and $25 \mu \mathrm{g} / \mathrm{mL})$ were added for 1 hour. Tert-butylhydroperoxide (t-BOOH) $1 \mathrm{mM}$ was used as an oxidation control and vitamin $\mathrm{C}(10 \mu \mathrm{g} / \mathrm{mL})$ was used as an antioxidant control. Then, fluorescence was measured at $485 \mathrm{~nm} / 528 \mathrm{~nm}$ (BioTek Synergy HT Multi-Mode Microplate Reader). A MTT assay was performed to normalize data by the number of cells per well. Experiments were carried out in triplicate.

To analyze the preventive effect of samples under induced oxidative stress conditions, cells were pretreated with caramel or the HMW fractions of CSE and SCG in FBS free medium for 24 hours. Then, the experiment was carried out as previously described but cells were treated simultaneously with samples and $\mathrm{t}-\mathrm{BOOH}(1 \mathrm{mM})$ to induce oxidative stress. Experiments were performed in triplicate and results were expressed as \% ROS.

\section{Statistical analysis}

Student's T test was carried out for the values obtained from the chemical characterization. One-way analysis of variance (ANOVA) was performed and statistical comparisons of the different treatments were performed using Tukey's test. Values of $p<0.05$ were considered 
statistically significant. All statistical analyses were performed using the IBM SPSS Statistics program version 23.

\section{RESULTS AND DISCUSSION}

Microbial safety of raw materials

Food safety is mandatory in order to develop a new food ingredient. However, no microbiological regulations have been stablished for coffee or coffee byproducts. Ochratoxin A (OTA) is one of the several naturally occurring mycotoxins produced by molds that grow on crops or during storage. It is the only mycotoxin subjected to European legislation being the maximum level of $5 \mu \mathrm{g} / \mathrm{kg}$ (European Commission (EC) 1881/2006). With regard to microbial safety of raw CSE, results showed values of $3.25 \times 10^{5} \mathrm{CFU} / \mathrm{g}$ for endospores, $4.3 \times 10^{3} \mathrm{CFU} / \mathrm{g}$ of total aerobic microorganisms and a content of yeasts and molds lower than $10^{2} \mathrm{CFU} / \mathrm{g}$. Results for raw SCG showed values below $10^{2} \mathrm{CFU} / \mathrm{g}$ for endospores, $10^{4} \mathrm{CFU} / \mathrm{g}$ of total aerobic microorganisms, content of yeasts lower than $10^{7} \mathrm{CFU} / \mathrm{g}$, and absence of molds. The absence of molds in our raw materials reduces the risk of OTA contamination. In addition, previous studies have confirmed values below $5 \mu \mathrm{g} / \mathrm{kg}$ for OTA $(<0.3 \mu \mathrm{g} / \mathrm{kg})$, and other hazardous mycotoxins such as aflatoxin B1 and enniatin B in CSE [4]. Therefore, considering microbial safety, CS and SCG present excellent microbiological quality and may be safe in order to be used as a food ingredient as a source of melanoidins.

\section{Physico-chemical characterization of HMW fractions}

UV-Visible spectral analysis

The UV-Visible spectra of caramel and the HMW fractions of CSE and SCG in the wavelength regions of $200-500 \mathrm{~nm}$ are shown in Figure 1. The obtained caramel UV-Vis absorption spectra was similar to that previously reported, in which the HMW caramels absorbed over the full wavelength range of $195-600 \mathrm{~nm}$ [17]. Measurement of absorption at 280, 325, and $405 \mathrm{~nm}$ provides useful information on the relative amount of melanoidins and other compounds in coffee samples [18]. In both HMW coffee byproduct fractions, two absorption maxima were observed at $280 \mathrm{~nm}$ and $325 \mathrm{~nm}$, being higher in the HMW-SCG sample. The absorption maximum at $280 \mathrm{~nm}$ in our samples has been also observed in coffee brew samples and it may correspond mostly to the presence of caffeine [18,19]. The absorption maxima at $280 \mathrm{~nm}$ can also be explained by the presence of proteins and phenolic acids. The maximum at $325 \mathrm{~nm}$ suggests the presence of chlorogenic and caffeic acid [19]. There is strong evidence that chlorogenic acid derivatives are components of coffee melanoidins [20]. Since chlorogenic acid is a low molecular weight compound $(<10 \mathrm{kDa})$, the observed maximum at $325 \mathrm{~nm}$ might correspond to the chlorogenic acid that forms coffee melanoidins. This absorbance maximum may be due to a contamination of chlorogenic acid that is non-covalently linked to the fiber structure of melanoidins. With additional washing steps after ultrafiltration, such as diafiltration, this contamination could be eliminated. It is generally accepted that melanoidins contain conjugated systems, which result is light absorption throughout the whole spectrum. On the basis of these absorption spectra, it can be stated that absorption measurements at 280,325 , and 405 provide useful information on the relative amounts of melanoidins and other compounds formed [21]. Polysaccharides, proteins and chlorogenic acids are involved in coffee melanoidin formation [20]. The progress of the Maillard reaction involves the production of final and HMW melanoidins with a chromophore group that absorbs around 420 $\mathrm{nm}$ [21]. Therefore, the suitable range for probing the presence of melanoidins can be delimited to the window between 405 and $420 \mathrm{~nm}$. Here, the absorption of other coffee compounds is rather 
negligible. Caramel and the HMW fractions obtained from coffee byproducts display a broad absorption around $405 \mathrm{~nm}$, which is in accordance to the characteristic brown color of melanoidins.

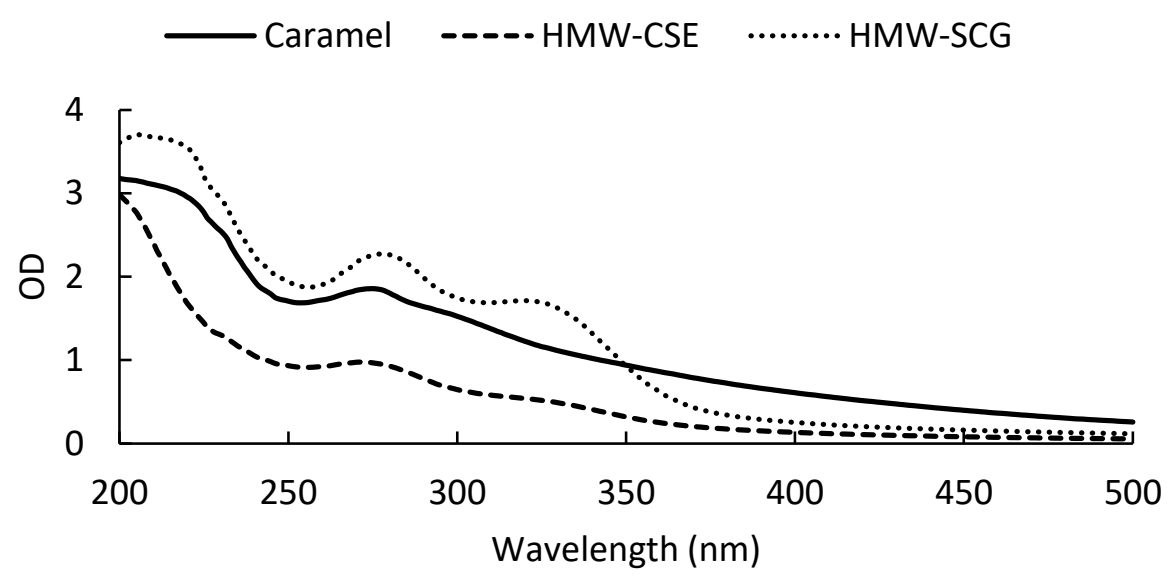

Figure 1. UV-Vis spectra of caramel and the HMW fractions of CSE and SCG at $0.5 \mathrm{mg} / \mathrm{ml}$.

\section{Infrared spectroscopy (IR)}

IR spectroscopy has been widely implemented for the molecular characterization and compound determination of green and roasted coffee beans [22]. In addition, IR spectroscopy also provides relevant information regarding bio-compound extraction [23]. Here, we report one of the first IR spectra of CSE (Figure 2B), SCG (Figure 2D) and corresponding HMW fractions (Figure 2C and 2E). The IR spectra of caramel (Figure 2A) was used as a standard reference. For the subsequent vibrational analysis we refer to previous publications [4].

Despite a similar brown coloring between caramel (Figure 2A) and the HMW melanoidin fractions, we observe a substantially distinct vibrational pattern. This also refers to the distinct band features of CSE (Figure 2D) and SGG (Figure 2E) melanoidin IR spectra. This suggests an overall specific content of melanoidinic precursors, while the macroscopic color prevails.

With regard to CSE, we observed a broad C-O feature with a maximum at $1022 \mathrm{~cm}^{-1}$, with local maxima at 1044, 1072 and $1096 \mathrm{~cm}^{-1}$. In addition, we observed another prominent at 1601 $\mathrm{cm}^{-1}$ with a shoulder at $1645 \mathrm{~cm}^{-1}$ and two high-frequency peaks at 1699 and $1734 \mathrm{~cm}^{-1}$. The first peaks corresponded to $\mathrm{C}=\mathrm{C}$ stretching features whereas the latter ones corresponded to $\mathrm{C}=\mathrm{O}$ stretching modes. These peaks could be assigned to the presence of lignin in the sample. Additionally, we observed a broad peak at $1406 \mathrm{~cm}^{-1}$ possibly a C-H2/CH3 flowering mode. In the high frequency region, we detected a poorly intense C-H stretching peaks at 2921 and $2851 \mathrm{~cm}^{-1}$ and a broad $\mathrm{O}-\mathrm{H}$ stretching peak at $3311 \mathrm{~cm}^{-1}$. After melanoidin extraction (Figure 2C), we did not observe a sustainable modification of the vibrational features, thus suggesting that the chemical composition prevails.

In contrast, SCG (Figure 2D) displayed a very strong and broadband envelope with a maximum at $1030 \mathrm{~cm}^{-1}$ and local maxima at 1012 and $1055 \mathrm{~cm}^{-1}$, containing mainly contributions of C-O stretching (C-O) coordinates of esters and alcohols. A similar feature is observed in the IR spectra of sugars, cellulose and melanoidins. At $1646 \mathrm{~cm}^{-1}$ and $1551 \mathrm{~cm}^{-1}$ were assigned to melanoidin-adduct modes or $\mathrm{C}=\mathrm{C}$ and imidazole stretching modes in caffeine, respectively (in red). These are characteristic peptide bond vibrational features, which, despite partial overlapping with further peaks, could be unambiguously assigned to the protein content in coffee beans (vide infra). To higher frequencies, two peaks at 1698 and $1742 \mathrm{~cm}^{-1}$ were observed. While both contained $\mathrm{C}=\mathrm{O}$ stretching coordinates $(\mathrm{C}=\mathrm{O})$, the frequency of the first one corresponded to peptide carbonyl $\mathrm{C}=\mathrm{O}$ modes (amide-I envelope) and the latter one was assigned to the stretching mode of an ester or a 
protonated carboxylic acid. In this respect, the evidence of two C-H stretching peaks at 2853 and $2921 \mathrm{~cm}^{-1}$ and the concomitant disappearance of these features upon extraction (Figure 2E) nicely correlated with the presence of a triglyceric fraction in SCG, commonly known as roasted coffee oil (green features in Figure 2D). Further peaks at 871 and $3009 \mathrm{~cm}^{-1}$ corresponded to this component. In the HMW fraction of SCG spectrum (Figure 2E), we observed that amide-I and II features as well as the broad peak at $1030 \mathrm{~cm}^{-1}$ remained unchanged, whereas the removal of fatty acid content allowed assignment to features at $1596 \mathrm{~cm}^{-1}$, containing $\mathrm{C}=\mathrm{C}$ stretching character and the rise of less prominent and broad peaks at 1373 and $1449 \mathrm{~cm}^{-1}(\mathrm{CH} 3 / \mathrm{CH} 2$ flowering vide infra). In the high frequency region, the broad $\mathrm{O}-\mathrm{H}$ stretching feature with maxima at 3348 and $3289 \mathrm{~cm}^{-}$ ${ }^{1}$ remained unchanged, whereas oil-removal led to the rise of a broad C-H stretching doublet at 2875 and $2929 \mathrm{~cm}^{-1}$. According to previous references, melanoidins had strong and broad O-H stretching peaks and poorly intense $\mathrm{C}-\mathrm{H}$ features [24].

Both HMW fractions of CSE and SCG, as well as the CSE displayed characteristic melanoidin-features. In addition, the two distinct samples of each extraction ( $\mathrm{m} 1$ and $\mathrm{m} 2$ ) displayed almost identical vibrational features (Figure 2C and 2E). The largest discrepancy was observed in the $\mathrm{O}-\mathrm{H}$ stretching region. While the CSE spectrum mainly displayed melanoidin-like features, the SCG spectrum was composed of a melanoidin and a protein component.

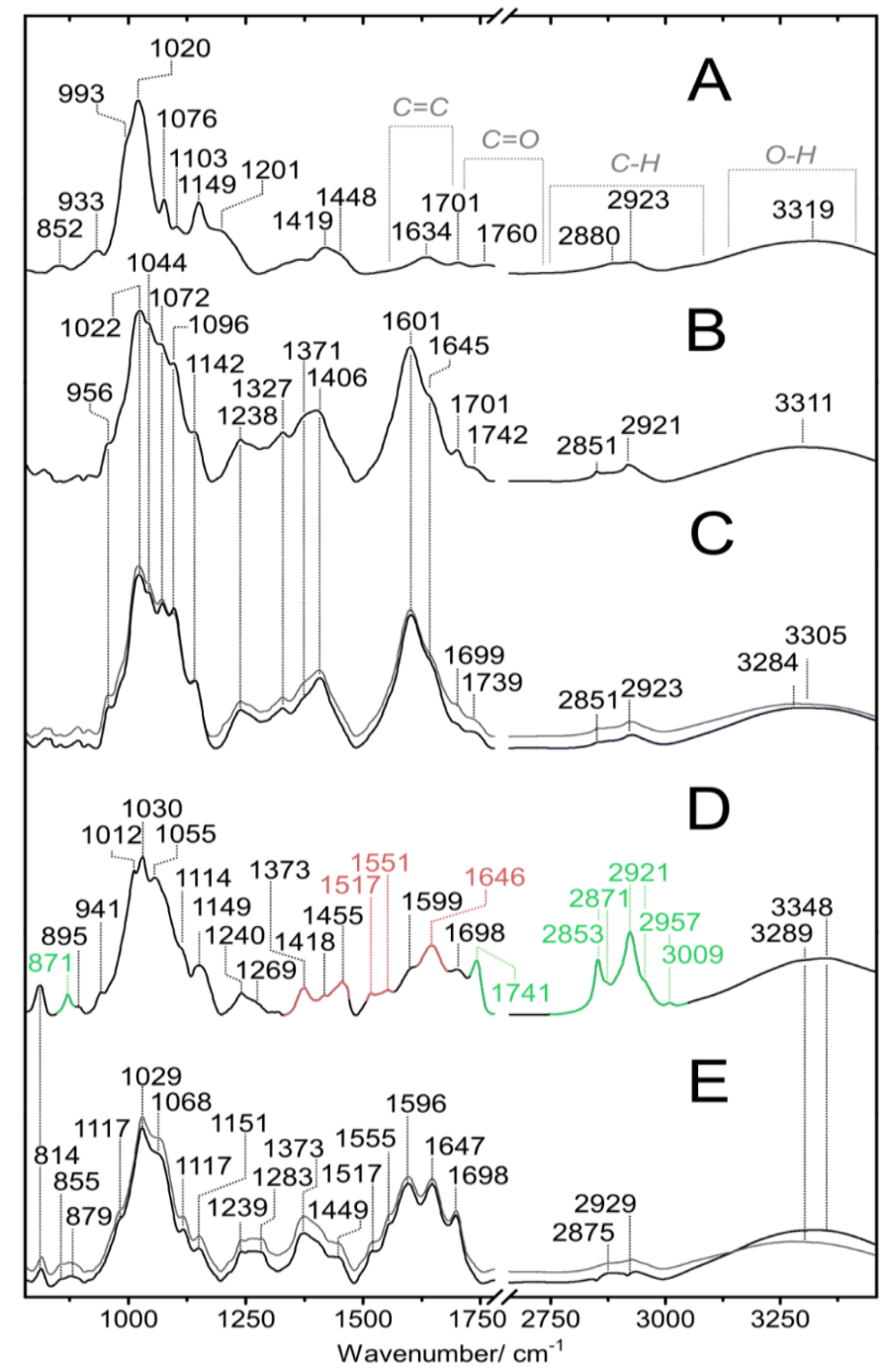

Figure 2. Infrared (IR) spectra of (A) caramel IV dye, (B) coffee silverskin (CS), (C) HMW fraction of coffee silverskin, (D) spent coffee grounds (SCG) and (E) HMW fraction of spent coffee 
grounds. For each HMW fraction (C and E) two independent spectra m1 (black) and $\mathrm{m} 2$ (grey) were recorded. All relevant band peaks are indicated. Protein (red) and fatty acid (green) contributions are also indicated. Characteristic IR regions with localized potential energy distribution (PED) such as $\mathrm{C}=\mathrm{C}, \mathrm{C}=\mathrm{O}, \mathrm{C}-\mathrm{H}$ and $\mathrm{O}-$ $\mathrm{H}$ stretching vibration modes are indicated.

\section{Chemical characterization of the HMW fractions}

Table 1 shows the chemical characterization of the HMW fractions of CSE and SCG. Results showed the presence of melanoidins absorbing at $405 \mathrm{~nm}$ in both HMW fractions of coffee byproduct samples. HMW-SCG showed significantly higher $(p<0.05)$ amount of melanoidins compared to HMW-CSE. Previous studies have reported the amount of melanoidins in these samples, around $4.5 \mathrm{~g} / 100 \mathrm{~g}$ for CS and between 13 and $25 \mathrm{~g} / 100 \mathrm{~g}$ for SCG [25,26]. Coffee melanoidins are diverse and they possess different physicochemical properties. The difference of melanoidin content in raw materials, together with the different species and the different nature of these two byproducts may explain the difference in melanoidin content in the HMW fractions obtained in this study. To the best of our knowledge, this is the first study that has analyzed and compared the HMW fraction of coffee byproducts.

Table 1. Chemical characterization of HMW coffee silverskin extract (CSE) and spent coffee grounds (SCG) melanoidin fractions.

\begin{tabular}{lll}
\hline Analysis & HMW-CSE & HMW-SCG \\
\hline Melanoidins (mg eq. caramel/g) & $215.79 \pm 0.010^{\mathrm{b}}$ & $345.96 \pm 0.003^{\mathrm{a}}$ \\
Protein (mg eq. BSA/g) & $18.44 \pm 1.25^{\mathrm{b}}$ & $73.96 \pm 3.93^{\mathrm{a}}$ \\
Total antioxidant capacity (mg eq. CGA/g) & $145.72 \pm 10.01^{\mathrm{b}}$ & $459.93 \pm 11.80^{\mathrm{a}}$ \\
Acrylamide $(\mu \mathrm{g} / \mathrm{kg})$ & $<20$ & $<20$ \\
Analysis & HMW-CSE & HMW-SCG \\
\hline Melanoidins (mg eq. caramel/g) & $215.79 \pm 0.010^{\mathrm{b}}$ & $345.96 \pm 0.003^{\mathrm{a}}$ \\
Protein $(\mathrm{mg}$ eq. BSA/g) & $18.44 \pm 1.25^{\mathrm{b}}$ & $73.96 \pm 3.93^{\mathrm{a}}$ \\
Total antioxidant capacity $(\mathrm{mg}$ eq. CGA/g) & $145.72 \pm 10.01^{\mathrm{b}}$ & $459.93 \pm 11.80^{\mathrm{a}}$ \\
Acrylamide $(\mu \mathrm{g} / \mathrm{kg})$ & $<20$ & $<20$ \\
\hline
\end{tabular}

Data are expressed as the means \pm standard deviation $(\mathrm{n}=3)$. Values in each row with different letters differ significantly (T test, $p<0.05$ ). BSA, bovine serum albumin; CGA, chlorogenic acid.

Table 1 also shows the total amount of soluble proteins found in HMW-CSE and HMW-SCG. Previous studies have confirmed the protein-rich composition of these byproducts [6]. In this study, protein content in HMW-SCG was significantly higher $(p<0.05)$ than that observed for HMWCSE, but values obtained were lower than that found for the original raw materials [6]. These results are in accordance to that observed in IR spectra analysis. It is known that the roasting process leads to protein denaturation with degradation and that protein breakdown into small fragments is a major event that takes place during coffee processing [3,27]. The different protein profile of green coffee and roasted coffee has been analyzed by SDS-PAGE. Green coffee presented two major protein bands at 58 and $38 \mathrm{kDa}$. However, roasted coffee presented a defined band at $\leq 14 \mathrm{kDa}$ and a diffuse band at $>200 \mathrm{kDa}$. This HMW band $>200 \mathrm{kDa}$ may correspond to proteins forming melanoidins [28]. 
The antioxidant capacity of HMW fractions of CSE and SCG is also shown in Table 1. HMWSCG possessed significantly higher $(p<0.05)$ antioxidant capacity compared to HMW-CSE. This difference in antioxidant properties may be due to the significantly higher $(p<0.05)$ content of melanoidins in HMW-SCG. It is known that coffee melanoidins (HMW fraction of coffee brews) present in vitro antioxidant capacity [27]. Chlorogenic acids non-covalently linked to the melanoidin skeleton may be important contributors to the overall antioxidant capacity of the HMW fractions of coffee brews [29]. However, melanoidin fractions without chlorogenic acids have also shown antioxidant capacity, suggesting that low molecular weight polyphenols linked to the central structure of the molecule are not the only contributors of melanoidin's antioxidant capacity [30]. Different results have been published on the effect of roasting on the antioxidant capacity of the melanoidin fractions isolated from coffee brews. With regard to results obtained from ABTS $^{+}$ assay, some authors have shown higher antioxidant capacity in lighter degrees of roast [27]. In contrast, other authors showed that the antioxidant activity of melanoidins isolated by ultrafiltration from instant coffees was lower in the light-roasted samples [29]. Further research regarding the study of melanoidin's structure is needed in order to better understand their antioxidant properties.

The presence of Maillard reaction products derived from lysine such as $N^{3}$-(fructosyl)lysine (FL), $N^{3}$-(carboxymethyl)lysine (CML) and $N^{3}$-(carboxyethyl)lysine (CEL), have been identified in the HMW fraction of coffee brews [31]. Therefore, the content of another product from the Maillard reaction derived from asparagine, acrylamide, was analyzed. Human population is widely exposed to acrylamide. This compound has been classified as a Group 2A carcinogen (probably carcinogenic to humans) by the International Agency for Research on Cancer (IARC) due to its neurotoxic, genotoxic, carcinogenic and reproductive toxicity properties [32]. As expected, levels $<20 \mu \mathrm{g} / \mathrm{kg}$ of acrylamide were found in HMW samples since this compound has low molecular weight (71.08 Da) (Table 2). Acrylamide content in samples was much lower than that established by the European Commission for roasted coffee $(400 \mu \mathrm{g} / \mathrm{kg})$ and instant coffee $(850 \mu \mathrm{g} / \mathrm{kg})$ [33]. The insignificant amounts found of acrylamide proved the food safety of our samples. Levels of 489 and $37 \mu \mathrm{g} / \mathrm{kg}$ of acrylamide have been previously found in CSE and SCG, respectively $[4,26]$. Since acrylamide is a water-soluble compound, it is normally transferred to the beverage during the brewing process [34]. This may explain the lower content of acrylamide in SCG compared to CSE.

\section{Cell studies}

Previous to the evaluation of the effect of HMW fraction of coffee byproducts on intracellular ROS, the effect of samples on cell viability was studied. Table 2 shows the viability of human fibroblasts isolated from normal colon tissue (CCD-18 cells) after 24 hours of incubation with HMW-CSE and HMW-SCG. Concentrations of 10 and $25 \mu \mathrm{g} / \mathrm{mL}$ were selected after previous preliminary studies. Caramel was again used as a melanoidin standard. None of the tested concentrations of HMW-CSE, HMW-SCG and caramel $(10 \mu \mathrm{g} / \mathrm{mL})$ resulted cytotoxic for CCD-18 cells $(p>0.05)$. No previous studies have reported the effect of melanoidins from coffee byproducts in healthy human colon fibroblasts.

Obtained results regarding the effect of the HMW fraction of CSE and SCG on the production of intracellular ROS on CCD-18 cells is shown in Figure 3. Cells treated with t-BOOH (oxidation control) presented significantly higher $(p<0.05)$ levels of intracellular ROS. Vitamin C $(10 \mu \mathrm{g} / \mathrm{ml})$ 
was included as an antioxidant standard and significantly reduced $(p<0.05)$ values of intracellular ROS. Caramel and samples significantly reduced $(p<0.05)$ levels of physiological intracellular ROS compared to non-treated cells (100\% ROS) (Figure 3A). No significant differences $(p>0.05)$ in the reduction of physiological intracellular ROS were observed between samples.

Table 2. Effect of $24 \mathrm{~h}$ treatment with noted concentrations of HMW fractions of coffee silverskin extract (CSE) or spent coffee grounds (SCG) in CCD-18 cells determined by the MTT assay. Control, non-treated cells. DMSO (50\%) was used as a death control.

\begin{tabular}{ll}
\hline Treatment & Cell viability (\%) \\
\hline Control & $100.0 \pm 8.5^{\mathrm{a}}$ \\
Death control & $6.0 \pm 1.1^{\mathrm{c}}$ \\
Caramel & \\
$\quad 10 \mu \mathrm{g} / \mathrm{ml}$ & $99.7 \pm 21.3^{\mathrm{a}}$ \\
$25 \mu \mathrm{g} / \mathrm{ml}$ & $70.9 \pm 13.9^{\mathrm{b}}$ \\
$\mathrm{HMW}-\mathrm{CSE}$ & $109.0 \pm 20.2^{\mathrm{a}}$ \\
$10 \mu \mathrm{g} / \mathrm{ml}$ & $86.9 \pm 10.7^{\mathrm{a}}$ \\
$25 \mu \mathrm{g} / \mathrm{ml}$ & \\
$\mathrm{HMW}-\mathrm{SCG}$ & $91.6 \pm 19.2^{\mathrm{a}}$ \\
$10 \mu \mathrm{g} / \mathrm{ml}$ & $89.4 \pm 18.0^{\mathrm{a}}$ \\
$25 \mu \mathrm{g} / \mathrm{ml}$ &
\end{tabular}

Data represent means \pm SD of 3 independent experiments. Different letters denote statistically significant differences between treatments (Tuckey test, $p<0.05$ ).

Once the harmless effect of the HMW fraction of coffee byproducts on cell viability and physiological intracellular ROS was confirmed, the potential protective effect against induced oxidative stress was studied (Figure 3B). A significant increase $(p<0.05)$ in ROS production was observed when cells were treated with $\mathrm{t}-\mathrm{BOOH} 1 \mathrm{mM}$ for 1 hour compared to non-stressed controls. Vitamin C $(10 \mu \mathrm{g} / \mathrm{ml})$ used as an antioxidant control also prevented the formation of induced intracellular ROS. Pretreatment of CCD-18 cells with caramel $(10 \mu \mathrm{g} / \mathrm{ml})$ and HMW-CSE and HMW-SCG (10 or $25 \mu \mathrm{g} / \mathrm{ml}$ ) for 24 hours prevented ROS production induced by t-BOOH, since a significant decrease $(p<0.05)$ in ROS levels was observed. Similar results regarding the absence of cytotoxicity and the effect of coffee melanoidins in the redox status of cells has been previously observed [35]. However, melanoidin samples used by these authors were obtained from coffee brews and were studied on liver cancer cells. In this study, melanoidins were obtained from a sustainable source since coffee byproducts are wastes generated by the coffee industry that are produced worldwide in large amounts and cause environmental problems.

Normal intestinal CCD-18 cells were used in this research. Although no previous studies have been published regarding the effect of coffee melanoidins in normal intestinal cells, other authors have studied melanoidins from different sources in different cell lines. For instance, Martín et al. (2009) have studied the effect of similar concentrations of biscuit melanoidins $(0.5-10 \mu \mathrm{g} / \mathrm{ml})$ in HepG2 liver cells. Authors observed a significant dose-response effect $(p<0.05)$ in the reduction of physiological intracellular ROS also using the DCFH-DA probe [36]. However, when HepG2 
cells were under oxidative stress conditions, biscuit melanoidins $<10 \mathrm{kDa}$ had no effect in the reduction of induced intracellular ROS. In contrast, when cells were pre-treated with intermediate mass biscuit melanoidins $(3-10 \mathrm{kDa})$, a significant decrease $(p<0.05)$ in induced intracellular ROS was observed [36]. When digested coffee melanoidins were studied also in HepG2 cells using the same approach, increased ROS generation induced by t-BOOH was not prevented [35]. In addition, melanoidins from thermally treated apricots protected endothelial cells, related to the development of cardiovascular diseases, from hydrogen peroxide-induced intracellular oxidation, mitochondrial depolarization and cell death [37].

\section{A}
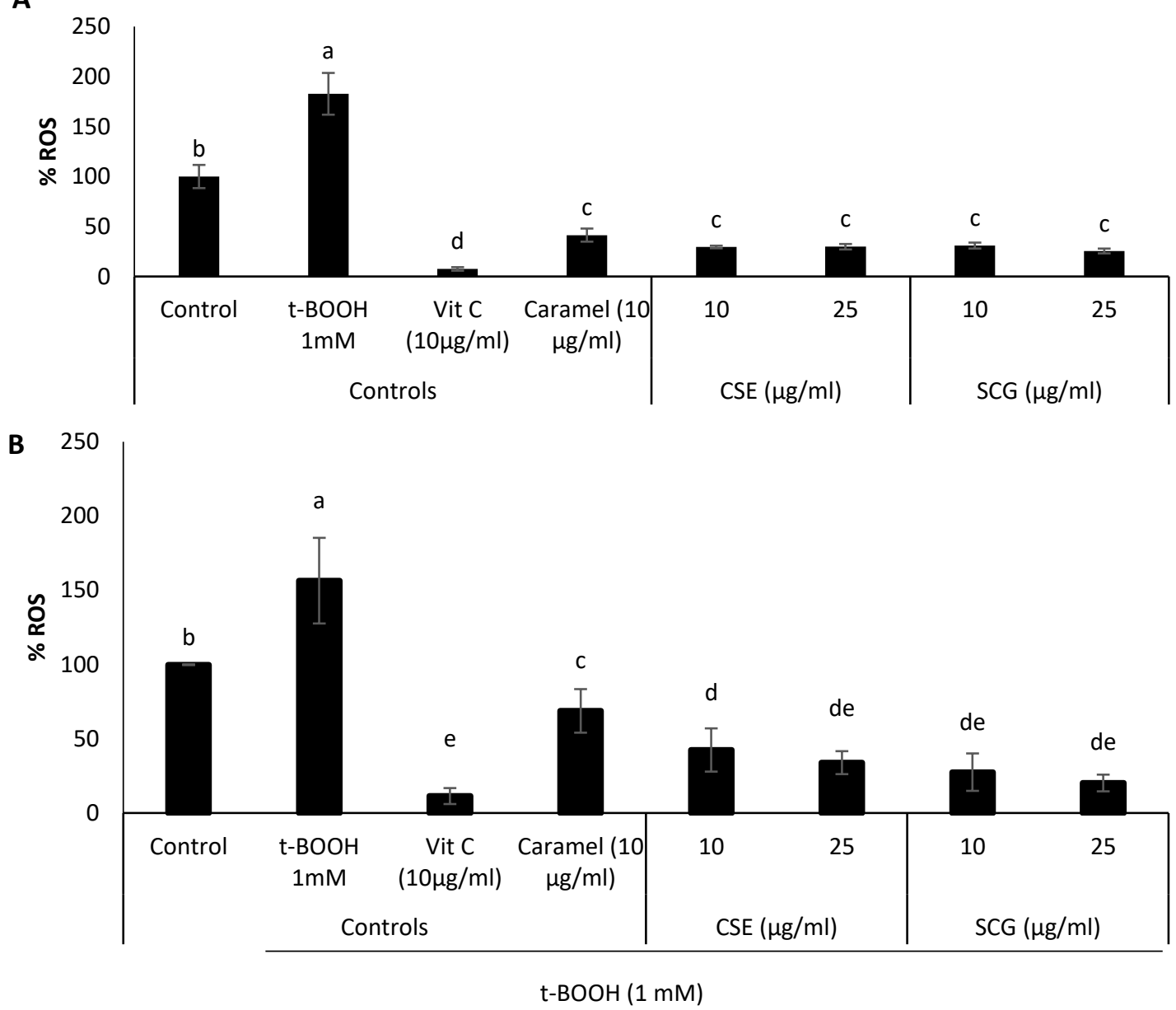

Figure 3. Effect of treatment with noted concentrations of caramel and HMW-CSE and HMWSCG on physiological (A) or induced (B) intracellular ROS in CCD-18 cells determined by the DCFH-DA probe. t-BOOH (1 mM) was used as oxidative damage control. Cells were pre-treated with samples or Vit C $(10 \mu \mathrm{g} / \mathrm{ml})$ for $24 \mathrm{~h}$ and incubated with the DCFH-DA probe for 30 minutes. Then, cells were treated with samples in absence (A) or presence (B) of t-BOOH $1 \mathrm{mM}$. Finally, fluorescence of intracellular ROS was measured, and data represent means \pm SD of 4 independent experiments. Different letters denote statistically significant differences between all treatments (Tukey test, $p<0.05$ ).

During coffee roasting melanoidins develop a more complex structure, which comprehends non-covalent incorporation of low molecular weight compounds such as chlorogenic acids to the initial backbone constituted by carbohydrates, including dietary fiber, polyphenols and proteins [7]. Therefore, melanoidins may be a type of "Maillardized dietary fiber" acting as dietary fiber with an overall antioxidant capacity leverage by embedded low molecular compounds [38]. Results 
obtained in this study indicate that melanoidins extracted from CSE and SCG possess in vitro antioxidant capacity and show protective effects against induced oxidative stress in intestinal cells. Consequently, melanoidins from coffee byproducts have great potential to be used as sustainable novel food ingredients to prevent or reduce the risk of gastrointestinal pathologies associated with oxidative stress. Further studies are required, especially to unveil a more accurate structural insight of these specific melanoidins' type. This detailed picture will substantially contribute to a comprehensive understanding of their potential health-promoting implications.

\section{CONCLUSIONS}

Two extracts enriched in melanoidins were obtained from coffee silverskin and spent coffee grounds. Both extracts have shown antioxidant properties in vitro and in normal human intestinal cells. Results suggest the use of the obtained sustainable antioxidant melanoidins as a novel functional ingredient with potential for reducing the risk of gastrointestinal pathologies associated with oxidative stress.

Abbreviations: ABTS, 2,2'-azinobis-(3-ethylbenzothiazoline-6-sulfonic acid); CS, coffee silverskin; CFU, colony-forming unit; DCFH-DA, 2',7'-dichlorodihydrofluorescein diacetate; DMEM, Dulbecco's Modified Eagle's Medium; DMSO, dimethyl sulfoxide; HMW, high molecular weight; IR, infrared spectroscopy; MTT, 3-(4,5-dimethylthiazole-y)-2,5diphenyltetrazolium bromide; OTA, ochratoxin A; PBS, phosphate buffered saline; ROS, reactive oxygen species; $\mathrm{SCG}$, spent coffee grounds; $\mathrm{tBOOH}$, tert-butyl hydroperoxide; $\mathrm{UV}$, ultraviolet.

Competing Interests: There are no conflicts of interest to declare.

Author Contributions: Methodology and Data Curation, A.I., B.R: and F.V.E.; Writing Original Draft Preparation and Writing-Review \& Editing, A.I., F.V.E. and M.D.C.; Supervision, Project Administration, Funding Acquisition and Writing-Review \& Editing, M.D.C.

Acknowledgements and Funding: The SUSCOFFEE Project (AGL2014-57239-R): Sustainable coffee production and consumption: Valorization of coffee waste into food ingredients funded this work. A. Iriondo-DeHond is a fellow of the FPI predoctoral program of MINECO (BES-2015-072191). F.VE. acknowledges the support of Prof. Dr. Peter Hildebrandt (TU Berlin). The authors thank the Servicio Interdepartamental de Investigación (SIdI UAM) for the analysis of acrylamide in samples.

\section{REFERENCES}

1. Belitz, HD, Grosch, W: Schieberle, P. Coffee, tea, cocoa. In: Food Chemistry. Eds. 4th edition, Springer, Leipzig; 2009; pp. 938-951.

2. Fogliano, V, Morales, FJ: Estimation of dietary intake of melanoidins from coffee and bread. Food Funct. 2011, 2, 117-123, DOI:10.1039/c0fo00156b.

3. Moreira, ASP, Nunes, FM, Domingues, MR, Coimbra, MA: Coffee melanoidins: 
structures, mechanisms of formation and potential health impacts. Food Funct. 2012, 3, 903-15, DOI:10.1039/c2fo30048f

4. Iriondo-DeHond, A., Aparicio Garcia, N., Velazquez Escobar, F., San Andres, M. I., Sanchez-Fortun, S., Blanch, G. P., Fernandez-Gomez, B., et al.: Validation of coffee by-products as novel food ingredients. Innov. Food Sci. Emerg. Technol. 2019, 51, 194-204.

5. Esquivel, P, Jimenez, VM: Functional properties of coffee and coffee by-products. Food Res. Int. 2012, 46, 488-495, DOI:10.1016/j.foodres.2011.05.028.

6. Mussatto SI, Machado EMS., Martins S., Teixeira JA: Production, Composition, and Application of Coffee and Its Industrial Residues. Food Bioprocess Technol. 2011, 4, 661-672, DOI:10.1007/s11947-011-0565-z.

7. Mesías, M., Delgado-Andrade, C: Melanoidins as a potential functional food ingredient. Curr. Opin. Food Sci. 2017, 14, 37-42, DOI: 10.1016/j.cofs.2017.01.007.

8. Pastoriza, S., Rufian-Henares, J. A: Contribution of melanoidins to the antioxidant capacity of the Spanish diet. Food Chem. 2014, 164, 438-445, DOI:10.1016/j.foodchem.2014.04.118.

9. Reichardt, N., Gniechwitz, D., Steinhart, H., Bunzel, M., Blaut, M: Characterization of high molecular weight coffee fractions and their fermentation by human intestinal microbiota. Mol. Nutr. Food Res. 2009, 53, 287-299, DOI:10.1002/mnfr.200700509.

10. Del Castillo, M. D., Ibanez, M. E., Amigo, M., Herrero, M., Plaza del Moral, M., Ullate, M: Application of products of coffee silverskin in anti-ageing cosmetics and functional food. WO 2013/004873 2013.

11. Sengar, G.; Sharma, H. K: Food caramels: a review. J. Food Sci. Technol. 2014, 51, 1686-1696, DOI:10.1007/s13197-012-0633-z.

12. Silvan, J. M., Morales, F. J., Saura-Calixto, F: Conceptual study on maillardized dietary fiber in coffee. J. Agric. Food Chem. 2010, 58, 12244-9, DOI:10.1021/jf102489u.

13. Oki, T., Nagai, S., Yoshinaga, M., Nishiba, Y., Suda, I: Contribution of b-Carotene to Radical Scavenging Capacity Varies among Orange-fleshed Sweet Potato Cultivars. Food Sci. Technol. Res 2006, 12, 156-160.

14. Re, R., Pellegrini, N., Proteggente, A., Pannala, A., Yang, M., Rice-Evans, C: Antioxidant activity applying an improved ABTS radical cation decolorization assay. Free Radic. Biol. Med. 1999, 26, 1231-1237, DOI:10.1016/S0891-5849(98)003153.

15. Bakondi, E., Gonczi, M., Szabo E., Bai, P., Pacher, P., Gergely, P., Kovács, L., et al.: Role of intracellular calcium mobilization and cell-density-dependent signaling in oxidative-stress-induced cytotoxicity in HaCaT keratinocytes. J. Invest. Dermatol. 2003, 121, 88-95, DOI:10.1046/j.1523-1747.2003.12329.x.

16. Gomes, A., Fernandes, E., Lima, J. L. F. C: Fluorescence probes used for detection of reactive oxygen species. J. Biochem. Biophys. Methods 2005, 65, 45-80, 
DOI:10.1016/j.jbbm.2005.10.003.

17. Royle, L., Radcliffe, C. M:Analysis of caramels by capillary electrophoresis and ultrafiltration. J. Sci. Food Agric. 1999, 79, 1709-1714, DOI:10.1002/(SICI)10970010(199909)79:12<1709::AID-JSFA425>3.0.CO;2-X.

18. Bekedam, E. K., Schols, H. A., Van Boekel, M. A. J. S., Smit, G: High Molecular Weight Melanoidins from Coffee Brew. J. Agric. Food Chem. 2006, 54, 7658-7666, DOI:10.1021/jf0615449.

19. Belay, A., Gholap, A: Characterization and determination of chlorogenic acids (CGA) in coffee beans by UV-Vis spectroscopy. African J. Pure Appl. Chem. 2009, 3, 234-240, DOI:10.5897/AJPAC.

20. Moreira, A. S. P., Nunes, F. M., Domingues, M. R., Coimbra, M. A: Coffee melanoidins: structures, mechanisms of formation and potential health impacts. Food Funct. 2012, 3, 903, DOI:10.1039/c2fo30048f.

21. Kang, OJ: Evaluation of melanoidins formed from black garlic after different thermal processing steps. Prev. Nutr. Food Sci. 2016, 21, 398-405, DOI:10.3746/pnf.2016.21.4.398.

22. Barbin DF, Felicio AL, De SM, Sun DW, Nixdorf SL, Hirooka EY: Application of infrared spectral techniques on quality and compositional attributes of coffee: An overview. Food Res. Int. 2014, 61, 23-32, DOI:10.1016/j.foodres.2014.01.005.

23. Lyman, D. J., Benck, R., Dell, S., Merle, S., Murray-Wijelath, J: FTIR-ATR analysis of brewed coffee: Effect of roasting conditions. J. Agric. Food Chem. 2003, 51, 32683272, DOI:10.1021/jf0209793.

24. Rubinsztain, Y., Yariv, S., Ioselis, P., Aizenshtat, Z., Ikan, R: Characterization of melanoidins by IR spectroscopy-I. Galactose-glycine melanoidins. Org. Geochem. 1986, 9, 117-125, DOI:10.1016/0146-6380(86)90101-4.

25. Borrelli, R. C., Esposito, F., Napolitano, A., Ritieni, A., Fogliano, V: Characterization of a new potential functional ingredient: coffee silverskin. J. Agric. Food Chem. 2004, 52, 1338-1343, DOI:10.1021/jf034974x.

26. Martinez-Saez, N., Tamargo Garcia, A., Dominguez Perez, I., Rebollo-Hernanz, M., Mesias, M., Morales, F. J., Martin-Cabrejas, M. A: Use of spent coffee grounds as food ingredient in bakery products. Food Chem. 2017, 216, 114-122, DOI:10.1016/j.foodchem.2016.07.173.

27. Borrelli, R. C., Visconti, A., Mennella, C., Anese, M., Fogliano, V: Chemical Characterization and Antioxidant Properties of Coffee Melanoidins. J. Agric. Food Chem. 2002, 50, 6527-6533, DOI:10.1021/jf025686o.

28. Nunes, F. M., Coimbra, M. A: Chemical characterization of the high molecular weight material extracted with hot water from green and roasted arabica coffee. J. Agric. Food Chem. 2001, 49, 1773-1782, DOI:10.1021/jf0012953.

29. Delgado-Andrade, C., Rufian-Henares, J. A., Morales, F. J: Assessing the antioxidant activity of melanoidins from coffee brews by different antioxidant methods. J. Agric. 
Food Chem. 2005, 53, 7832-7836, DOI:10.1021/jf0512353.

30. Gniechwitz, D., Reichardt, N., Meiss, E., Ralph, J., Steinhart, H., Blaut, M., Bunzel, M: Characterization and fermentability of an ethanol soluble high molecular weight coffee fraction. J. Agric. Food Chem. 2008, 56, 5960-5969, DOI:10.1021/jf800231q.

31. Nunes, F. M., Coimbra, M. A: Melanoidins from coffee infusions. Fractionation, chemical characterization, and effect of the degree of roast. J. Agric. Food Chem. 2007, 55, 3967-3977, DOI:10.1021/jf063735h.

32. European Food Safety Authority Scientific Opinion on acrylamide in food. EFSA J. 2015, 13, 4104, DOI:10.2903/j.efsa.2015.4104.

33. European Commission COMMISSION REGULATION (EU) 2017/2158 of 20 November 2017 establishing mitigation measures and benchmark levels for the reduction of the presence of acrylamide in food. Off. J. Eur. Union 2017, 204, 24-44

34. Stadler, R. H., Theurillat, V: Acrylamide in Coffee. Coffee Emerg. Heal. Eff. Dis. Prev. 2012, 259-273, DOI:10.1002/9781119949893.ch15.

35. Goya, L., Delgado-Andrade, C., Rufián-Henares, J. a, Bravo, L., Morales, F. J: Effect of coffee melanoidin on human hepatoma HepG2 cells. Protection against oxidative stress induced by tert-butylhydroperoxide. Mol. Nutr. Food Res. 2007, 51, 536-545, DOI:10.1002/mnfr.200600228.

36. Martin, M. A., Ramos, S., Mateos, R., Rufian-Henares, J. A., Morales, F. J., Bravo, L., Goya, L: Biscuit melanoidins of different molecular masses protect human HepG2 cells against oxidative stress. J. Agric. Food Chem. 2009, 57, 7250-7258, DOI:10.1021/jf9006032.

37. Cossu, A., Posadino, A. M., Giordo, R., Emanueli, C., Sanguinetti, A. M., Piscopo, A., Poiana, M, et al.: Apricot Melanoidins Prevent Oxidative Endothelial Cell Death by Counteracting Mitochondrial Oxidation and Membrane Depolarization. PLoS One 2012, 7, DOI:10.1371/journal.pone.0048817.

38. Silvan, J. M., Morales, F. J., Saura-Calixto, F: Conceptual Study on Maillardized Dietary Fiber in Coffee. J. Agric. Food Chem. 2010, 58, 12244-12249, DOI:10.1021/jf102489u. 